\title{
Irrigação e certificação da cafeicultura na Região Centro-Oeste de São Paulo
}

\author{
Marcos José Perdoná $\left({ }^{1,4 *}\right)$; Rogério Peres Soratto $\left({ }^{2}\right)$; Adriana Novais Martins $\left({ }^{3}\right)$; Eduardo Suguino \\ (1); Mauricio Antonio Cuzato Mancuso ( $\left.{ }^{4}\right)$ \\ (') Agência Paulista de Tecnologia dos Agronegócios (APTA Regional/SAA), Av. Bandeirantes, 2419, 14030-670 Ribeirão Preto (SP), Brasil. \\ (2) Universidade Estadual Paulista Júlio de Mesquita Filho (UNESP/FCA), Departamento de Produção Vegetal, Caixa Postal 237. \\ 18603-970 Botucatu (SP), Brasil. \\ (3) APTA Regional/SAA, Rua Andrade Neves, 81, 17515-400 Marília (SP), Brasil. \\ (4) UNESP/FCA, Programa de Pós-Graduação em Agronomia (Agricultura), 18603-970 Botucatu (SP), Brasil. \\ (*) Autor correspondente: marcosperdona@apta.sp.gov.br; marcos.perdona@yahoo.com.br
}

Recebido: 17/jan./2012; Aceito: 8/ago./2012

\begin{abstract}
Resumo
Rentabilidade insatisfatória tem provocado diminuição paulatina do parque cafeeiro no Estado de São Paulo. Entre as alternativas para a solução deste problema, duas se destacam: a irrigação das lavouras e a certificação das propriedades. Mesmo em regiões consideradas aptas à cultura do café arábica (Coffea arabica L.), o uso da irrigação pode promover, na média dos anos, aumento de produtividade de grãos. Além disso, a certificação do produto favorece sua diferenciação no mercado e pode melhorar os resultados econômicos da atividade. Este trabalho teve por objetivo avaliar o desenvolvimento e a produtividade de cafeeiros submetidos a sistemas irrigados ou não, comparando os dados econômicos na comercialização do café certificado ou não, nas condições da Região Centro-Oeste do Estado de São Paulo. O delineamento utilizado no campo foi o de blocos ao acaso, com dois tratamentos (com e sem irrigação por gotejamento) e dez repetições. Foram calculados os custos de produção, bem como a lucratividade com a venda do produto final. A irrigação aumentou o desenvolvimento e a produtividade dos cafeeiros. Houve o retorno do investimento a partir da terceira safra. A venda de café certificado possibilitou resultados econômicos em média de $224,5 \%$ superiores ao não certificado. A irrigação aliada à venda de café certificado proporcionou saldo financeiro 1.192\% superior ao café não irrigado e não certificado.
\end{abstract}

Palavras-chave: Coffea arabica L., deficiência hídrica, gotejo, Fair trade, lucratividade.

\section{Irrigation and certification on coffee crop in mid-west of São Paulo State, Brazil}

\section{Abstract}

An unsatisfactory profitability has led to the gradual decline of the coffee plantations in São Paulo. Among the alternatives that arise for solving this problem, two stand out: the irrigation of crops and certification of properties. Even in areas considered suitable for cultivation of arabica coffee (Coffea arabica L.), the use of irrigation can promote an increase in grain yield. In addition, the product certification promotes their differentiation in the market and can improve the economic results of the activity. This study aimed to evaluate the development and productivity of coffee crops subjected to irrigation or not, comparing economic data in the marketing of coffee certified or not, under the conditions of the mid-west region of São Paulo state. The field experimental design was in randomized blocks with two treatments (with and without drip irrigation) and ten repetitions. The costs of production and profitability by selling the final product were calculated. The irrigation increased the development and productivity of coffee. The return on investment took place after the third harvest. Irrigation combined with the sale of certified coffee provided financial balance 1,192\% higher than the coffee is not irrigated and non-certified.

Key words: Coffea arabica L., water deficit, drip, Fair trade, profitability. 


\section{INTRODUÇÃO}

A cafeicultura desenvolveu-se no Estado de São Paulo em localidades com condiçóes de solo, temperatura, altitude e disponibilidade hídrica, consideradas favoráveis à cultura. Desse modo, a não necessidade do uso da irrigação foi considerada por muito tempo como uma vantagem econômica na produção em relação às outras regiôes do país. A adoçáo da irrigaçáo do cafeeiro surgiu com o avanço da cultura para áreas consideradas marginais ao cultivo quanto às necessidades hídricas, tais como as regióes de cerrado, entre elas o Triângulo Mineiro e o Oeste Baiano, onde se tem alcançado elevadas produtividades, com alta qualidade (Alves et al., 2000). Na safra 2011, a média de produtividade da regiáo do cerrado do Triângulo Mineiro foi de 42,48 sacas ha ${ }^{-1}$, contra 20,94 sacas ha ${ }^{-1}$ no Estado de São Paulo (CONAB, 2011). Gomes et al. (2007) obtiveram 45,12 sacas ha $^{-1}$ e 22,5 sacas ha ${ }^{-1}$, respectivamente, em lavouras irrigadas e não irrigadas no Sul de Minas, região também considerada com déficit hídrico aceitável para a cafeicultura. Para Carvalho et al. (2006), a ocorrência de deficiência hídrica compromete a produção dos cafeeiros, fato comprovado por meio de respostas positivas observadas com o uso da irrigação nos locais acima relacionados.

Nas regiôes consideradas aptas à cafeicultura, a ocorrência de estiagens (veranicos) nas fases críticas de demanda de água pela cultura tem promovido reduçáo significativa na produção. Assim, a suplementaçáo hídrica em áreas tradicionais de cultivo de café pode ser justificada (Alves et al., 2000). Estudos demonstram que há grande influência da irrigação no desenvolvimento das plantas (diâmetro do caule, copa, altura e número de ramo), em diversas regiôes cafeeiras no Brasil (Alves et al. 2000; Faria e Siqueira, 2005; Carvalho et al, 2006; Costa et al. 2010). Aspectos relativos à produtividade também foram avaliados em diversos locais, sempre com resultados favoráveis aos cultivos irrigados (Silva et al., 2008; Lima et al., 2008).

Em Campinas (SP), em pesquisas realizadas durante 16 safras, verifica-se que a produção da lavoura irrigada foi superior. Observou-se grande variaçáo na produtividade e nas diferenças entre o tratamento irrigado e o de sequeiro ao longo dos anos (Arruda e Grande, 2003). Além disso, a irrigaçáo por gotejamento da cultura do café, em regióes com condiçôes pluviométricas favoráveis à produção, foi viável economicamente. Esse fato elevou consideravelmente os indicadores econômicos e reduziu o tempo de recuperação do capital investido, promovendo significativo aumento da atratividade de investimento, pois a maior eficiência do sistema produtivo proporciona maiores lucros (ArÊDES et al, 2010; Oliveira et al., 2010).

$\mathrm{Na}$ Região Centro-Oeste do Estado de Sáo Paulo, a crise de preços iniciada da década de 1990 levou parte dos produtores a alterar os sistemas produtivos, adotando melhores técnicas de manejo como, por exemplo, o cultivo irrigado (Esperancini e Paes, 2005). Contudo, esta é uma tecnologia que requer investimentos representativos (Silva et al., 2003) e grande parte do seu sucesso depende do manejo adequado do sistema (Lima et al., 2008), condiçóes que nem sempre podem ser cumpridas por pequenos produtores, que representam a maior parte da cafeicultura paulista. Além do aumento na produtividade, os cafeicultores têm como alternativa a busca por mercados diferenciados para melhorar sua renda.

O café é produto que possui grande potencial para diferenciação, tal como o vinho ou mesmo a água mineral, que já foram produtos considerados comuns no passado, e que nas últimas décadas passaram a ocupar um mercado sofisticado com diversos atributos (SAES, 2007). A diferenciação, através da certificação dos produtos, é uma forma de se conseguir melhores preços (Kaplinsky e FitTer, 2001), sendo esta uma maneira de alcançar mercados específicos, com agregaçáo de valor ao produto final. Uma das mais importantes para a agricultura familiar é a certificação Fair Trade, que estabelece um preço mínimo, cobrindo os custos de produção e oferecendo margem maior de lucro (Pereira et al., 2006).

Embora o desenvolvimento do comércio justo tenha sido iniciado após a Segunda Guerra mundial e represente nova forma de inserção de pequenas organizaçóes de produtores rurais no mercado internacional, a discussão sobre o tema na literatura acadêmica tem sido limitada e os pesquisadores têm dedicado pouca atenção ao assunto (BouroulLeC e Paulillo, 2010). O mercado para café certificado Fair Trade tem crescido de forma elevada em todo o mundo; entre 2000 e 2005; este mercado passou de 0,2 para 2,2\% do total de café comercializado (DORAN, 2008).

Assim, considerando a realidade da cafeicultura na região, este trabalho teve por objetivo avaliar a produtividade de cafeeiros submetidos a sistemas sem e com irrigação e comparar os resultados econômicos na comercialização do café certificado ou não, nas condiçôes do CentroOeste paulista.

\section{MATERIAL E MÉTODOS}

O experimento foi instalado no sítio São Pedro, localizado no município de Dois Córregos, Regiāo Centro-Oeste do Estado de São Paulo, com latitude 22²1'S, longitude $48^{\circ} 22^{\prime} \mathrm{W}$, altitude $753 \mathrm{~m}$.

O delineamento utilizado no campo foi o de blocos ao acaso, com dois tratamentos (com e sem irrigaçáo) e dez repetiçóes, sendo cada parcela composta por cinco plantas, considerando as três centrais como parcela útil $\left(3,75 \mathrm{~m}^{2}\right)$. As mudas de café arábica (Coffea arabica L.), cultivar Obatá (IAC 1669-20), foram transplantadas em fevereiro de 2006, no espaçamento 3,5x0,7 m, em área anteriormente cultivada com pastagem, sendo o solo classificado como Latossolo Vermelho-Amarelo distrófico (LVAd) (EMBRAPA, 1999). 
Os resultados de análises química, da camada de 0-0,20 $\mathrm{m}$ de profundidade, antes da instalaçáo do experimento, foram: 5,2 para $\mathrm{pH}\left(\mathrm{CaCl}_{2}\right) ; 5 \mathrm{mg} \mathrm{dm}^{-3}$ de fósforo - P(resina); $17 \mathrm{~g} \mathrm{dm}^{-3}$ de matéria orgânica - M.O.; $0,8 \mathrm{mmol}_{\mathrm{c}} \mathrm{dm}^{-3}$ de potássio $-\mathrm{K} ; 9,0 \mathrm{mmol}_{\mathrm{c}} \mathrm{dm}^{-3}$ de cálcio - Ca; $7 \mathrm{mmol} \mathrm{dm}^{-3}$ de magnésio $-\mathrm{Mg} ; 1 \mathrm{mmol}_{\mathrm{c}} \mathrm{dm}^{-3}$ de alumínio - Al; $18 \mathrm{mmol}_{\mathrm{c}} \mathrm{dm}^{-3}$ de hidrogênio + alumínio - $\mathrm{H}+\mathrm{Al}$; $49 \%$ de saturação por bases; $3 \mathrm{mg} \mathrm{dm}^{-3}$ de enxofre $-\mathrm{S}_{-} \mathrm{SO}_{4}^{2-} ; 0,12 \mathrm{mg} \mathrm{dm}^{-3}$ de boro $-\mathrm{B}$ (Água quente); $0,4 \mathrm{mg} \mathrm{dm}^{-3}$ de cobre - Cu (DTPA); $20 \mathrm{mg} \mathrm{dm}^{-3}$ de ferro - Fe (DTPA); 3,6 $\mathrm{mg} \mathrm{dm}^{-3}$ de manganês - Mn (DTPA) e $0,6 \mathrm{mg} \mathrm{dm}^{-3}$ de zinco - Zn (DTPA), e da análise física: $10,3 \%$ de argila, $7,1 \%$ de silte e $82,6 \%$ de areia, com classificação textural muito arenosa.

As correçôes de solo e adubaçōes realizadas seguiram as indicações para cultura do cafeeiro no Estado de São Paulo (RAIJ et al., 1996). Antes do plantio, foram distribuídos e incorporados ao solo $1.300 \mathrm{~kg} \mathrm{ha}^{-1}$ de calcário dolomítico. Além disso, foi aplicado em superfície mais $1.000 \mathrm{~kg} \mathrm{ha}^{-1}$ de calcário dolomítico, em 2008 e em 2010. As adubaçóes de NPK foram padronizadas e calculadas anualmente, tendo como base as análises de solo e a idade das plantas ou estimativas de safra de cada ano no tratamento irrigado. No plantio, foram distribuídos e incorporados em cada metro de sulco, $60 \mathrm{~g}$ de $\mathrm{P}_{2} \mathrm{O}_{5}, 20 \mathrm{~g}$ de $\mathrm{K}_{2} \mathrm{O}$ e $5 \mathrm{~L}$ de cama de frango. $\mathrm{Na}$ adubação de primeiro ano, foram aplicados $40 \mathrm{~g}$ de $\mathrm{P}_{2} \mathrm{O}_{5}, 40 \mathrm{~g}$ de $\mathrm{K}_{2} \mathrm{O}$, parcelados em cinco adubaçóes e, nos anos seguintes, as quantidades de $\mathrm{N}-\mathrm{P}_{2} \mathrm{O}_{5}-\mathrm{K}_{2} \mathrm{O}$, em kg ha-1 ${ }^{-1}$ foram 160-50-160 (2007/08); 250-60-200 (2008/09); 500-80-500 (2009/10) e 16050-160 (2010/11). Em cada ano agrícola também foram realizadas quatro pulverizaçóes com boro, cobre e zinco.

Segundo a classificação de Köppen, o clima da região é caracterizado como Cwa, tropical, com estação seca no inverno, temperatura média anual de $21,2^{\circ} \mathrm{C}$ e regime pluviométrico anual médio de $1.342 \mathrm{~mm}$ (CEPAGRI, 2010).
Os dados climatológicos da região, no período de desenvolvimento deste trabalho, são apresentados na tabela 1 .

O sistema de irrigação por gotejamento foi instalado em fevereiro de 2006, anterior ao plantio das mudas, sendo composto de um conjunto moto-bomba, filtro de disco, manômetros e linhas de irrigação com tubos flexíveis de polietileno e gotejadores autocompensantes, espaçados $0,7 \mathrm{~m}$ entre si, ou seja, um gotejador por planta, e vazão de $1,0 \mathrm{~L} \mathrm{~h}^{-1}$ em cada gotejador.

O manejo da irrigação foi feito utilizando-se o sistema Irrigas (SANTANA et al., 2004). Na escolha do sistema de manejo da irrigação, optou-se por aquele que oferecesse fácil manejo e reduzida manutenção. A lâmina de água aplicada foi definida em função de sensores de tensão de água de $25 \mathrm{kPa}$ instalados em profundidades de 0,20 e $0,60 \mathrm{~m}$, as leituras (seco e úmido) foram feitas diariamente, mantendo-se sempre úmido o sensor instalado a $0,20 \mathrm{~m}$, com um tempo de irrigação de 6 horas, acionado manualmente, com exceçấo para os meses de julho e agosto, quando a irrigação foi suprimida a partir de 2008, com o objetivo de se obter uma uniformização das floradas (Guerra et al., 2005). Em 2006, 2007, 2008, 2009 , 2010 e 2011 foram aplicados, respectivamente, 155, 237, $321,167,288$ e $152 \mathrm{~mm}$ de água via irrigação.

Em fevereiro de cada ano, foram realizadas as seguintes avaliaçóes: diâmetro do caule (medido a 0,05 m de altura em relaçáo à superfície do solo com paquímetro) e altura da planta (determinada da superfície do solo ao meristema apical). As avaliaçôes de produtividade de café beneficiado foram realizadas nas quatro primeiras safras, ou seja, em 2008, 2009, 2010 e 2011. Os dados foram submetidos à análise de variância pelo teste $\mathrm{F}$, a 5\% de probabilidade.

As planilhas de custo de produção foram elaboradas considerando os parâmetros adotados pela publicação Anuário da Agricultura Brasileira (Agrianual, 2009), considerando os encargos financeiros sobre o custeio e investimento. As

Tabela 1. Dados médios mensais de temperatura e precipitação pluvial, no período de fevereiro de 2006 a julho de 2011, em Dois Córregos (SP)

\begin{tabular}{|c|c|c|c|c|c|c|c|c|c|c|c|c|}
\hline \multirow{2}{*}{ Mês } & \multicolumn{2}{|c|}{2006} & \multicolumn{2}{|c|}{2007} & \multicolumn{2}{|c|}{2008} & \multicolumn{2}{|c|}{2009} & \multicolumn{2}{|c|}{2010} & \multicolumn{2}{|c|}{2011} \\
\hline & TM & PP & TM & PP & TM & PP & TM & PP & TM & PP & TM & PP \\
\hline & $\left({ }^{\circ} \mathrm{C}\right)$ & $(\mathrm{mm})$ & $\left({ }^{\circ} \mathrm{C}\right)$ & $(\mathrm{mm})$ & $\left({ }^{\circ} \mathrm{C}\right)$ & $(\mathrm{mm})$ & $\left({ }^{\circ} \mathrm{C}\right)$ & $(\mathrm{mm})$ & $\left({ }^{\circ} \mathrm{C}\right)$ & $(\mathrm{mm})$ & $\left({ }^{\circ} \mathrm{C}\right)$ & $(\mathrm{mm})$ \\
\hline Jan. & - & - & 24,7 & 433,8 & 24,0 & 199,8 & 24,1 & 398,7 & 25,2 & 236,7 & 26,3 & 434,7 \\
\hline Fev. & 25,3 & 202,5 & 25,3 & 221,4 & 24,7 & 194,4 & 25,4 & 175,5 & 25,6 & 160,2 & 26,5 & 153 \\
\hline Mar & 25,5 & 232,2 & 25,7 & 150,3 & 24,6 & 162,9 & 25,1 & 160,2 & 24,7 & 143,1 & 25,0 & 188,1 \\
\hline Abr. & 22,4 & 33,3 & 24,9 & 93,6 & 23,0 & 162 & 23,0 & 23,4 & 23,2 & 66,6 & 23,5 & 91,8 \\
\hline Maio & 18,5 & 0,9 & 19,5 & 67,5 & 19,3 & 79,2 & 20,7 & 74,7 & 20,1 & 24,3 & 19,7 & 11,7 \\
\hline Jun. & 19,3 & 16,2 & 20,5 & 10,8 & 19,0 & 52,2 & 17,2 & 51,3 & 18,7 & 17,1 & 18,6 & 36,9 \\
\hline Jul. & 20,8 & 45,9 & 18,2 & 272,7 & 19,7 & 0 & 19,5 & 92,7 & 20,5 & 54,9 & 19,8 & 4,5 \\
\hline Ago. & 21,9 & 14,4 & 21,0 & 0 & 22,0 & 48,6 & 19,5 & 86,4 & 20,3 & 0 & 19,8 & 74,7 \\
\hline Set. & 21,4 & 67,5 & 24,3 & 0 & 21,1 & 52,2 & 22,2 & 228,6 & 22,9 & 77,4 & - & - \\
\hline Out. & 23,8 & 167,4 & 24,7 & 75,6 & 23,6 & 115,2 & 22,3 & 93,6 & 22,8 & 92,7 & - & - \\
\hline Nov. & 25,0 & 232,2 & 23,6 & 274,5 & 24,2 & 79,2 & 25,8 & 263,7 & 24,9 & 85,5 & - & - \\
\hline Dez. & 25,1 & 298,8 & 24,1 & 271,8 & 24,2 & 129,6 & 23,9 & 356,4 & 25,6 & 325,8 & - & - \\
\hline
\end{tabular}

TM: temperatura média. PP: precipitaçăo pluvial. 
quantidades de insumos e operaçóes foram tomadas da área em questáo. Os valores dos insumos e serviços foram atualizados para a safra de 2011. Os valores de venda dos cafés foram obtidos em pesquisa na Associaçáo dos Produtores de Café de Dois Córregos (UNICAFÉ), para café com certificação Fair Trade (R \$ 591,00 saca-1) e sem certificação ( $\left.\mathrm{R} \$ 483,00 \mathrm{saca}^{-1}\right)$, sendo consideradas os valores médios das vendas realizadas entre junho e setembro de 2011.

\section{RESULTADOS E DISCUSSÃO}

Para todas as variáveis avaliadas, houve diferença entre os tratamentos irrigados e náo irrigados, nos quatro anos de estudo (Tabelas 2 e 3). Para uma região com déficit hídrico que ultrapassa $100 \mathrm{~mm}$ anuais, nas plantas irrigadas, observaram-se maiores valores de diâmetro do caule e de altura (Tabela 2), uma vez que os processos metabólicos e, consequentemente, o desenvolvimento das plantas, na condição sem irrigação, fica restrito nos períodos de deficiência hídrica. Resultados semelhantes, nestas variáveis, também foram verificados por CarvalHo et al. (2006) e Rezende et al. (2010), quando avaliaram irrigação em cafeeiros localizados em Lavras (MG) e Maringá (PR) respectivamente. Os resultados observados por estes autores evidenciaram os efeitos benéficos da irrigação no desenvolvimento de cafeeiros nestas regiôes também consideradas aptas para a cafeicultura náo irrigada, como a deste estudo.

Os valores de diâmetro do caule foram de alta correlação com a altura da planta $(r=0,89$ e $\mathrm{p}<0,001)$. Observase que as plantas não irrigadas podem ter menor altura e diâmetro do caule, quando comparadas às plantas que receberam suplementação hídrica, uma vez que a restrição de água pode afetar os processos metabólicos e, consequentemente, o crescimento das plantas (CARvalho et al., 2006).

Baixos valores de potencial de água das plantas ( $\Psi$ wa) não irrigadas podem reduzir significativamente o número de flores se comparadas com as plantas irrigadas, com reflexos na produtividade de gráos; por esse motivo, a irrigação é uma das alternativas mais adotadas nos últimos tempos para aumentar a produtividade na cafeicultura (SILVA et al., 2003; 2009). No presente trabalho, apesar de não se ter os dados de $\Psi_{w a}$, os incrementos em produtividade obtidos pelo uso da irrigaçáo foram evidentes, na ordem de $159,7 \%, 51,8 \%$ e $26,5 \%$, respectivamente, para os três primeiros anos de colheita (Tabela 3). Costa et al. (2010) também trabalharam com cafeeiros Obatã em MaringáPR e obtiveram incremento de produção da ordem de $80 \%$ na primeira safra, com a utilização da irrigação.

Para Mera et al. (2011), a suspensão da irrigação por 70 dias após a colheita e anterior ao florescimento proporcionou maior uniformidade de florescimento e maturação, maior número de frutos por ramo e produtividade de grãos. Neste trabalho, em contraste com os anos anteriores, no período em que foram submetidas à deficiência hídrica para uniformização da florada, em julho e agosto de 2010, observou-se amarelecimento de folhas, nas plantas irrigadas; e em seguida ocorreu a queda, ocasionando exaustão das plantas, que estavam com alta carga pendente $\left(82,83\right.$ saca ha $\left.^{-1}\right)$, com reflexo na produção do ano seguinte (2011), levando à produtividade de 5,83 sacas inferior ao tratamento náo irrigado (Tabela 3 ).

Tabela 2. Diâmetro do caule e altura das plantas de café cv. Obatã (IAC 1669-20), em 2008, 2009, 2010 e 2011, com e sem irrigação, em Dois Córregos (SP)

\begin{tabular}{|c|c|c|c|c|}
\hline \multirow{3}{*}{ Tratamento } & \multicolumn{4}{|c|}{ Ano } \\
\hline & 2008 & 2009 & 2010 & 2011 \\
\hline & \multicolumn{4}{|c|}{ Diâmetro do caule (mm) } \\
\hline Irrigado & $42,2 \mathrm{a}$ & $47,1 \mathrm{a}$ & $52,5 \mathrm{a}$ & $67,23 \mathrm{a}$ \\
\hline Não irrigado & $37,7 \mathrm{~b}$ & $44,1 \mathrm{~b}$ & $47,9 \mathrm{~b}$ & $62,50 \mathrm{~b}$ \\
\hline \multirow[t]{2}{*}{$\mathrm{CV}(\%)$} & 5,2 & 6,0 & 6,3 & 6,0 \\
\hline & \multicolumn{4}{|c|}{ Altura da planta $(\mathrm{m})$} \\
\hline Irrigado & $1,00 \mathrm{a}$ & $1,45 \mathrm{a}$ & 1,99 a & $2,31 \mathrm{a}$ \\
\hline Não irrigado & $0,73 b$ & $1,29 \mathrm{~b}$ & $1,70 \mathrm{~b}$ & $2,01 \mathrm{~b}$ \\
\hline CV(\%) & 10,0 & 5,1 & 9,6 & 5,0 \\
\hline
\end{tabular}

Médias seguidas da mesma letra na coluna nâo diferem entre si pelo teste $\mathrm{F}$, a 5\% de probabilidade.

Tabela 3. Produtividade de grãos beneficiados (sc ha $\left.{ }^{-1}\right)$ de café cv. Obatã (IAC 1669-20), em 2008, 2009, 2010 e 2011 , com e sem irrigação, em Dois Córregos (SP)

\begin{tabular}{|c|c|c|c|c|c|}
\hline \multirow{2}{*}{ Tratamento } & \multicolumn{4}{|c|}{ Ano } & \multirow{2}{*}{ Média } \\
\hline & 2008 & 2009 & 2010 & 2011 & \\
\hline Irrigado & $26,10 \mathrm{a}$ & $47,75 \mathrm{a}$ & 82,83 a & $15,30 \mathrm{~b}$ & $42,99 a$ \\
\hline Não irrigado & $10,05 \mathrm{~b}$ & $31,46 \mathrm{~b}$ & $65,49 \mathrm{~b}$ & $21,13 a$ & $32,03 \mathrm{~b}$ \\
\hline CV(\%) & 14,1 & 7,5 & 12,2 & 20,1 & 7,5 \\
\hline
\end{tabular}

Médias seguidas da mesma letra na coluna não diferem entre si pelo teste $\mathrm{F}$, a $5 \%$ de probabilidade. 
Em trabalhos realizados em Lavras (MG), Coelho et al. (2009) verificaram maiores produtividades quando as plantas não foram submetidas ao estresse hídrico de $1 .^{\circ}$ de junho a 30 de setembro, enquanto Gomes et al. (2007) verificaram que a irrigação não foi capaz de evitar a ocorrência da bienalidade na produção em Lavras (MG), concordando com os resultados deste trabalho. Lima et al. (2008) também verificaram que na quarta safra a produtividade do tratamento testemunha atingiu os valores dos tratamentos irrigados devido, provavelmente, à redução da produtividade em funçáo da bienalidade para os tratamentos irrigados e, também, ao possível esgotamento fisiológico dessas plantas que obtiveram produtividades elevadas desde a primeira safra, quando ainda estavam em formação.

Considerando apenas os três primeiros anos de produção, foram constatadas correlaçôes positivas da altura da planta $(r=0,93$ e $\mathrm{p}<0,001)$ e o diâmetro do caule $(r=0,79$ e $\mathrm{p}<0,001)$ com a produtividade de gráos. Plantas mais robustas e mais altas, em geral, possuem maior número de ramos plagiotrópicos e, consequentemente, maior potencial produtivo (ArÊDES et al., 2010).

Contudo, devido ao maior efeito da deficiência hídrica para a uniformização da florada nas plantas do tratamento com irrigação, em 2010, que levou à menor produtividade de grãos na safra seguinte, além da intensificação da bienalidade, houve, no último ano (2011), correlaçóes negativas da altura da planta $(r=-0,67$ e $\mathrm{p}=0,001)$ e o diâmetro do caule $(\mathrm{r}=-0,82$ e $\mathrm{p}<0,001)$ com a produtividade. Tais resultados evidenciam que, em solos de textura arenosa, como é o caso deste trabalho, a supressão da irrigação por um período de 70 dias durante o período de seca, recomendado por GuerRa et al. (2005), pode reduzir a produtividade da cultura do café arábica e acentuar a bienalidade da produção em relaçáo às lavouras de sequeiro.

Mesmo assim, no tratamento irrigado, o acréscimo da produtividade, na média dos dois biênios avaliados, foi de $34,2 \%$, em relação ao tratamento não irrigado (Tabela 3), corroborando Arruda e Grande (2003), Lima et al. (2008), Silva et al. (2008) e Oliveira et al. (2010), que também trabalharam em regiôes consideradas aptas para o cultivo do café, sem irrigação. O maior aumento de produtividade com o uso da irrigação foi obtido logo na primeira safra, quando as plantas não irrigadas foram drasticamente afetadas pelo déficit hídrico (Tabela 3).

Resultados diferentes foram avaliados por ARRUDA e GRANDE (2003), quando observaram que o ajuste do coeficiente de sensibilidade ou fator de resposta da produção do cafeeiro ao déficit hídrico, Ky, estava linearmente crescente com a idade da planta, indicando aumento quanto à sensibilidade ao déficit hídrico ao longo dos anos. Tal diferença pode ser explicada em parte pela diferença na capacidade de retenção de água dos solos estudados. Assim, sob as condiçōes de solos arenosos deste experimento (82,6\% de areia), plantas jovens submetidas à irrigação tiveram maior diferencial de produtividade comparadas às não irrigadas que aquelas estudadas por ArRUdA e Grande (2003), em solos com 55\% de argila, com maior capacidade de armazenamento de água.

Com relação aos custos das lavouras, no sistema irrigado, os valores unitários são mais elevados quando comparados com o sistema convencional (Tabela 4), devido à maior intensidade do uso de insumos e máquinas, além dos custos gerados pela prática de irrigaçáo (ARÊDEs et al., 2010). Com gastos maiores na instalação e manutenção da lavoura, parte das divisas foi comprometida, e assim os investimentos retornaram somente a partir da terceira safra para os dois tratamentos, mesmo com as maiores produtividades e maior ingresso de divisas obtidas pela venda do produto, no tratamento irrigado (Tabela 4).

De acordo com ArÊDEs et al. (2007), a elevação do nível de produtividade resultante de uma lavoura de café irrigada gera benefícios econômicos superiores aos custos oriundos da adoçáo desta tecnologia.

Mesmo com os valores de investimento na instalação e manutenção da irrigação sendo computados, os melhores valores de renda foram obtidos no tratamento irrigado, os quais desde a primeira safra propiciaram resultados mais favoráveis. Este fato pode ter ocorrido, uma vez que os custos totais médios foram inversamente proporcionais às produtividades dos tratamentos, e, de acordo com SiLva et al. (2003), podem indicar resposta favorável à escala de produção.

Considerando apenas a situação de café não certificado, no sistema não irrigado os resultados foram positivos a partir da terceira safra e superados pelo irrigado em $561 \%$, no fim de dois biênios de produção, sendo o último mais compensador, apesar do maior investimento inicial, corroborando Esperancini e PAEs (2005). Embora eleve o custo total final, a produçáo irrigada diminui o custo médio de produção por saca e eleva o retorno econômico, reduzindo o tempo de recuperação do capital investido e o risco da atividade (ARÊDEs et al., 2010).

$\mathrm{Na}$ tabela 4, é possível avaliar o desempenho econômico dos tratamentos irrigado e não irrigado, considerando os custos da certificaçáo da propriedade e dos valores recebidos pelos cafés certificados na safra 2011. A propriedade onde se realizou o presente estudo é certificada pela Fair Trade Labelling Organizations International (FLO) e comercializa cafés Fair Trade, com diferenciais de preços recebidos pelos produtores que chegaram ao máximo de $\mathrm{R} \$ 120,00$ por saca no ano de 2010 (arquivos de venda de café da safra 2011 da UNICAFE) e retornaram para patamares mais baixos no ano seguinte. Assim, é importante considerar que o ágio pago para o café certificado Fair Trade é variável, podendo nem sempre atingir patamares tão elevados. Os padrões de funcionamento do comércio justo estão fundamentados em critérios sociais, econômicos e ecológicos. Esses critérios são voluntariamente aceitos pelas organizaçóes, o que os levam a realizar certos investimentos específicos nas propriedades (Bouroullec e Paulillo, 2010). 
Considerando os seis primeiros anos, a certificação proporcionou resultados de $95 \%$ e $354 \%$ superiores para os tratamentos irrigados e não irrigados respectivamente, em comparaçáo com o café não certificado, ou seja, vendido no mercado "commodity" (Tabela 4). Tal fato foi possível porque a certificação Fair Trade é direcionada, sobretudo, a pequenos produtores e não exige deles grandes investimentos em modificaçōes das estruturas das propriedades, mas sim mudanças de atitude, tais como aprendizados sobre trabalhos em associação com outros produtores, treinamentos sobre leis e segurança no trabalho, leis ambientais e planejamento da propriedade, mobilizando bastante tempo, porém poucos recursos efetivos dos proprietários.
Bouroullec e Paulillo (2010) apontam o aprendizado de novas competências, o que integra o conhecimento das exigências sociais, econômicas e ecológicas do comércio justo como investimento específico para obtenção da certificação. Resultam em mudanças, em alguns aspectos ligados à produção, ao transporte e à estocagem. Assim, com pequenos investimentos e boa remuneração pelo produto, a certificação passou a ser uma alternativa viável, equiparando até os valores de renda líquida obtida no tratamento de sequeiro ao irrigado náo certificado, com alternativa de menor investimento inicial.

Os melhores resultados, porém, foram obtidos pela associação da tecnologia de irrigação e a venda de café certificado, que proporcionaram saldo financeiro positivo

Tabela 4. Custos e receitas dos seis anos iniciais de lavoura de café cv. Obatã (IAC 1669-20) com e sem irrigaçáo, certificados e não certificados, em Dois Córregos (SP), de 2006 a 2011

\begin{tabular}{|c|c|c|c|c|c|c|}
\hline \multirow[t]{3}{*}{ Custos/Receitas } & Ano 1 & Ano 2 & Ano 3 & Ano 4 & Ano 5 & Ano 6 \\
\hline & \multicolumn{6}{|c|}{$\left(\mathrm{R} \$ h^{-1}\right)$} \\
\hline & \multicolumn{6}{|c|}{ Não irrigado - Não certificado } \\
\hline A - Operações & 2639,50 & 864,70 & 2358,70 & 4578,72 & 7418,88 & 3776,06 \\
\hline B - Insumos e Materiais & 4352,90 & 1119,52 & 2213,62 & 2723,09 & 3785,21 & 2923,77 \\
\hline C - Administração & 825,00 & 1729,40 & 936,65 & 1174,49 & 1552,53 & 826,12 \\
\hline Custo Operacional Efetivo & 7817,40 & 3713,62 & 5508,96 & 8476,30 & 12756,62 & 7525,95 \\
\hline Custo Operacional Total & 8501,42 & 4038,56 & 5990,99 & 9217,98 & 13872,82 & 8184,47 \\
\hline Custo Total de produção & 10210,47 & 5501,37 & 7561,53 & 10966,55 & 15878,22 & 9876,03 \\
\hline Receita Bruta & - & - & 4854,15 & 15195,18 & 31631,67 & 10205,79 \\
\hline \multirow[t]{2}{*}{ Resultados Acumulados } & $-10210,47$ & $-15711,84$ & $-18419,22$ & $-14190,60$ & 1562,86 & 1892,62 \\
\hline & \multicolumn{6}{|c|}{ Irrigado - Não certificado } \\
\hline A - Operações & 2626,10 & 864,70 & 3262,48 & 5674,20 & 9109,46 & 3706,10 \\
\hline B - Insumos e Materiais & 4342,50 & 1119,52 & 2578,88 & 3299,53 & 4659,72 & 2900,45 \\
\hline C - Administração & 1038,90 & 1729,40 & 1417,03 & 1775,98 & 2227,58 & 825,81 \\
\hline Custo Operacional Efetivo & 8007,50 & 3713,62 & 7258,38 & 10749,70 & 15996,76 & 7432,36 \\
\hline Custo Operacional Total & 9058,16 & 4388,56 & 8243,49 & 12040,30 & 17746,47 & 8432,69 \\
\hline Custo Total de produção & 10778,61 & 5851,37 & 9918,99 & 13925,28 & 19946,28 & 10118,63 \\
\hline Receita Bruta & - & - & 12601,47 & 23063,25 & 40006,89 & 7389,90 \\
\hline \multirow[t]{2}{*}{ Resultados Acumulados } & $-10778,61$ & $-16629,98$ & $-13947,50$ & $-4809,54$ & 15251,08 & 12522,34 \\
\hline & \multicolumn{6}{|c|}{ Não irrigado - Certificado } \\
\hline A - Operações & 2639,50 & 864,70 & 2358,70 & 4578,72 & 7418,88 & 3776,06 \\
\hline B - Insumos e materiais & 4352,90 & 1119,52 & 2261,12 & 2829,97 & 4185,96 & 2923,77 \\
\hline C - Administração & 825,00 & 1729,40 & 961,61 & 1252,64 & 1715,21 & 825,00 \\
\hline D - Certificação & 1200,00 & 600,00 & 600,00 & 600,00 & 600,00 & 1800,00 \\
\hline Custo Operacional Efetivo & 9017,40 & 4313,62 & 6181,42 & 9261,32 & 13920,05 & 9324,83 \\
\hline Custo Operacional Total & 9806,42 & 4691,06 & 6722,30 & 10071,69 & 15138,05 & 10140,75 \\
\hline Custo Total de produção & 11587,47 & 6189,87 & 8333,18 & 11867,37 & 17213,25 & 11940,24 \\
\hline Receita Bruta & - & - & 5939,55 & 18592,86 & 38704,59 & 12487,83 \\
\hline \multirow[t]{2}{*}{ Resultados Acumulados } & $-11587,47$ & $-17777,34$ & $-20170,97$ & $-13445,48$ & 8045,86 & 8593,45 \\
\hline & \multicolumn{6}{|c|}{ Irrigado - Certificado } \\
\hline A - Operações & 2626,10 & 864,70 & 3262,48 & 5674,20 & 9109,46 & 3706,10 \\
\hline B - Insumos e materiais & 4342,50 & 1119,52 & 2578,88 & 3299,53 & 4659,72 & 2900,45 \\
\hline C - Administração & 1038,90 & 1729,40 & 1481,83 & 1894,59 & 2433,32 & 825,00 \\
\hline D - Certificação & 1200,00 & 600,00 & 600,00 & 600,00 & 600,00 & 1800,00 \\
\hline Custo Operacional Efetivo & 9207,50 & 4313,62 & 7923,19 & 11468,31 & 16802,50 & 9231,55 \\
\hline Custo Operacional Total & 10363,16 & 5041,06 & 8966,47 & 12821,79 & 18622,72 & 10389,31 \\
\hline Custo Total de produção & 12155,61 & 6539,87 & 10681,86 & 14749,89 & 20870,87 & 12183,20 \\
\hline Receita Bruta & - & - & 15419,19 & 28220,25 & 48952,53 & 9042,30 \\
\hline Resultados Acumulados & $-12155,61$ & $-18695,48$ & $-13958,15$ & $-487,79$ & 27593,87 & 24452,96 \\
\hline
\end{tabular}


de $\mathrm{R} \$ 24.452,96$ por hectare, ou seja, $1.192 \%$ superior ao café não irrigado e não certificado, sistema mais utilizado pelos cafeicultores brasileiros.

\section{CONCLUSÃO}

A utilização da irrigação favoreceu o desenvolvimento, com aumento de produtividade dos cafeeiros da Região Centro-Oeste paulista. O retorno do investimento iniciou-se a partir da terceira safra, tanto no sistema irrigado, como no não irrigado. A venda de café certificado possibilitou resultados econômicos superiores ao não certificado, justificando o investimento dos produtores no processo de certificação. A irrigação, aliada à venda de café certificado, proporcionou o maior saldo financeiro positivo, com benefícios ao cafeicultor, no decorrer das safras avaliadas.

\section{AGRADECIMENTO}

Ao CNPq pela concessão de bolsa de Produtividade em Pesquisa para o segundo autor.

\section{REFERÊNCIAS}

ANUÁRIO DA AGRICULTURA BRASILEIRA - AGRIANUAL. Café. São Paulo: Instituto FNP, 2009. p.225-226.

ALVES, M.E.B.; FARIA, M.A.; GUIMARÃES, R.J.; MUNIZ, J.A.; SILVA, E.L. Crescimento do cafeeiro sob diferentes lâminas de irrigação e fertirrigação. Revista Brasileira de Engenharia Agrícola e Ambiental, v.4, p.219-225, 2000.

ARÊDES, A.F.; SANTOS, M.L.; RUFINO, J.L.S.; REIS, B.S. Viabilidade econômica da irrigaçáo da cultura do café na regiáo de Viçosa-MG. Revista de Economia e Agronegócio, v.5, p.207-225, 2007.

ARÊDES, A.F.; PEREIRA, M.W.G.; SANTOS, M.L. A irrigação do cafezal como alternativa econômica ao produtor. Acta Scientiarum Agronomy, v.32, p.193-200, 2010.

ARRUDA, F.B.; GRANDE, M.A. Fator de resposta da produção de cafeeiro ao déficit hídrico em Campinas. Bragantia, v.62, p.139-145, 2003.

BOUROULLEC, M.D.M.; PAULILlO, L.F. Governanças híbridas complementares aos contratos no comércio justo citrícola internacional. Gestão e Produção, v.17, p. 61-773, 2010.

CARVALHO, C.H.M.; COLOMBO, A.; SCALCO, M.S.; MORAIS, A.R. Evoluçáo do crescimento do cafeeiro (Coffea arabica L.) irrigado e não irrigado em duas densidades de plantio. Ciência e Agrotecnologia, v.30, p.243-250, 2006.

CENTRO DE PESQUISAS METEOROLÓGICAS E CLIMÁTICAS APLICADAS À AGRICULTURA - CEPAGRI.
Clima dos municípios paulistas. Disponível em <http://www.cpa. unicamp.br/outras-informações/clim_muni_279.html>. Acesso em: 18/1/2010

COELHO, G.; SILVA, A.M.; REZENDE, F.C.; SILVA, R.A.; CUSTÓDIO; A.A.P. Efeitos de época de irrigação e de parcelamento de adubaçáo sobre a produtividade do cafeeiro 'Catuaî'. Ciência e Agrotecnologia, v.33, p.67-73, 2009.

COMPANHIA NACIONAL DE ABASTECIMENTO CONAB. Central de informaçóes agropecuárias. Disponível em: <http://www.conab.gov.br/conabweb/download/safra/estudo_ safra.pdf>. Acesso em: 2/5/2011.

COSTA, A.R.; REZENDE, R.; FREITAS, P.S.L.; FRIZZONE, J.A.; HELBEL JUNIOR., C. Número de ramos plagiotrópicos e produtividade de duas cultivares de cafeeiro utilizando irrigação por gotejamento. Revista Ciência Agronômica, v.41, p.571-581, 2010.

DORAN, C.J. The role of personal values in Fair Trade consumption. Journal of Business Ethics, v.84, p.549-563, 2008.

EMPRESA BRASILEIRA DE PESQUISA AGROPECUÁRIA EMBRAPA. Centro Nacional de Pesquisa de Solos (Rio de Janeiro, RJ). Sistema Brasileiro de Classificação dos Solos. Brasília: Embrapa SPI; Rio de Janeiro: Embrapa Solos, 1999. 412p.

ESPERANCINI, M.S.; PAES A.R. Analise de investimentos da produção de café nos sistemas irrigado e convencional na região de Botucatu, Estado de São Paulo. Informaçôes Econômicas, v.35, p. 52-60, 2005.

FARIA, R.T.; SIQUEIRA, R. Produtividade do cafeeiro e cultivos intercalares sob diferentes regimes hídricos. Bragantia, v.64, p. $583-590,2005$.

GUERRA, A.F.; ROCHA, O.C.; RODRIGUES, G.C. Manejo do cafeeiro irrigado no Cerrado com estresse hídrico controlado. Irrigação \& Tecnologia Moderna, n.65/66, p.42-45, 2005.

GOMES, N.M.; LIMA L.A.; CUSTÓDIO A.A.P. Crescimento vegetativo e produtividade do cafeeiro irrigado no sul do Estado de Minas Gerais. Revista Brasileira de Engenharia Agrícola e Ambiental, v.11, p.564-570, 2007.

KAPLINSKY, R.; FITTER, R. Technology and globalization: who gains when commodities are de commodified? Journal of Technology and Globalization, v.1, p.5-28, 2001.

LIMA, L.A.; CUSTÓDIO, A.A.P.; GOMES, N.M. Produtividade e rendimento do cafeeiro nas cinco primeiras safras irrigado por pivô central em Lavras, MG. Ciência e Agrotecnologia, v.32, p.1832-1842, 2008.

MERA, A.C.; OLIVEIRA, C.A.S.; GUERRA, A.F.; RODRIGUES, G.C. Regimes hídricos e doses de fósforo em cafeeiro. Bragantia, v.70, p.302-311, 2011.

OLIVEIRA, E.L.; FARIA, M.A.; REIS, R.P.; SILVA, M.L.O. Manejo e viabilidade econômica da irrigação por gotejo na cultura do cafeeiro Acaiá considerando seis safras. Engenharia Agrícola, v.30, p.887-896, 2010. 
PEREIRA, S.P.; BLISKA, F.M.M.; ROCHA, A.B.O. Certificação de comércio justo e solidário (Fair Trade): princípios, requisitos e dinâmica no Brasil, 2006. Disponível em: <http://www.cafepoint. com.br>. Acesso em: 12/9/2011.

RAIJ, B. van; CANTARELLA, H.; QUAGGIO, A.J. Estimulantes. In: RAIJ, B. van; QUAGGIO, A.J.; CANTARELLA, H.; FURLANI, A.M.C. Recomendaçốes de adubação e calagem para o Estado de São Paulo. Campinas: IAC, 1996. p.97-101. (Boletim Técnico, 100)

REZENDE, R.; HELBEL JUNIOR, C.; SOUZA, R.S.; ANTUNES, F.M.; FRIZZONE, J.A. Crescimento inicial de duas cultivares de cafeeiros em diferentes regimes hídricos e dosagens de fertirrigação. Engenharia Agrícola, v.30, p.447-458, 2010.

SAES, M.S.M.A Distribuição de quase-renda e a estratégia de diferenciação no café. Revista de Administração Contemporânea, v.11, p.151-171, 2007.

SANTANA, M.S.; OLIVEIRA, C.A.S.; QUADROS, M. Crescimento inicial de duas cultivares de cafeeiro adensado influenciado por níveis de irrigação localizada. Revista Brasileira de Engenharia Agrícola e Ambiental, v.24, p.644-653, 2004.

SILVA, A.L.; FARIA, M.A.; REIS, R.P. Viabilidade técnicoeconômica do uso do sistema de irrigação por gotejamento na cultura do cafeeiro. Revista Brasileira de Engenharia Agrícola e Ambiental, v.7, p.37-44, 2003.

SILVA, A.C.; SILVA, A.M.; COELHO, G.; REZENDE, F.C.; SATO, F.A. Produtividade e potencial hídrico foliar do cafeeiro Catuaí, em função da época de irrigação. Revista Brasileira de Engenharia Agrícola e Ambiental, v.12, p.21-25, 2008.

SILVA, E.A.; BRUNINI, O.; SAKAI, E.; ARRUDA, F.B.; PIRES, R.C.M. Influência de déficits hídricos controlados na uniformização do florescimento e produção do cafeeiro em três diferentes condiçóes edafoclimáticas do Estado de São Paulo. Bragantia, v.68, p.493-501, 2009. 